\title{
An Analysis of English Translation of Collocations in Sa'di's Orchard: A Comparative Study
}

\author{
Shima Ebrahimi (Corresponding author) \\ Linguistics Department, Ferdowsi University of Mashhad, PO box 91779-48974, Park Square, Mashhad, Iran \\ Fahimeh Lesan Toosi \\ Translation Department, Ferdowsi University of Mashhad, PO box 91779-48974, Park Square, Mashhad, Iran
}

\begin{abstract}
To most of the theorists, the aesthetic function of language is the most difficult function when translating it into another culture. In translation of poetry as a special type of aesthetic function of language, the translator deals with two parts; the form and the function. The emphasis put on each of these reveals the strategy that the translator has adopted. One problematic aspect of poetry is caused by the subtleties of language which are demonstrated differently in different cultures. In creation of these subtleties, definitely, linguistic tools are involved. Collocations are among these tools which allow the poets to use their wit. To translate collocations, translator should be aware of its features to recognize them in the poem and also its types in order to decide what approach to take.
\end{abstract}

Index Terms - form, function, aesthetic function, translation of poetry, collocation

\section{INTRODUCTION}

Literary translation is one of the hotly debated fields far from reaching a consensus as to whether a work of literature is translatable or untranslatable. The major problem in translating a piece of literary work especially in the form of poetry is unconventional linguistic devices employed by the poet to make it different from ordinary texts. These devices are mostly unique and specific to the poet and can be derived from a particular culture, religion, belief and so on. Therefore, they are used in totally different ways in different languages and cultures.

Collocations as one of these devices used by poets require considerable attention when appear in a text to be translated. Since they are considered one of the subtleties of language, we can guess how effective cultural information of the source text could be in grasping the meaning of collocations in that they are like many other aspects of language, highly culture-bound. This feature of collocations makes them complex and difficult to understand. Another reason for complexity of collocations when attempting to translate them lies in various ways they can be translated for different purposes. Thus, a translator should reach to a complete understanding of collocations and their contexts of use in both SL and TL.

\section{A. What is a collocation?}

Collocations are defined by Firth as linguistic phenomena to be meaning-based rather than grammar-based. Firth (1968), Halliday and Hassan (1976) claim that collocation is a group of words used to develop lexical cohesion of text and contain "a cohesive force". Regarding the degree of cohesiveness of lexical combination, Benson et al (1986) defines collocations to be "fixed phrases" stored in the mind.

In Sinclair's view (1991) a collocational structure is a co-occurrence of two or more words within a short space of each other in a piece of discourse. The notion of collocation is similarly referred to as a sequence of two or more consecutive words with a particular relation between them in a way that it has the characteristics of a single unit whose meaning cannot be extracted from the meaning or connotation of its components.

\section{B. Grasping the Meaning of Collocations}

Regarding the meaning of collocations, Stubbs (1995) recommends that "there are always semantic relations between node and collocates, and among the collocations themselves". It is noteworthy that Cruse (1989) defines collocation as "sequences of lexical items which habitually co-occur". According to him, these sequences shape a semantic constituent. Cruse believes context as a crucial factor in expressing the meaning of semantic constituents. He also claims that the transferred meaning is restricted to the context. Similarly, Firth (1957) argues that "you shall know a word by the company it keeps" Thus, in translating a text the translator should be careful about these relations since he either seeks to break them to use the components in a new context and new form or as an alternative, tends to find a suitable correspondence in TL. 


\section{REVIEW OF THE LITERATURE}

Numerous studies have been carried based on collocations and collocational relations. Lyons (1997) believes that a collocation should be considered as a whole and that separating its components does not give a legitimate meaning equal to the combination of them.

Halliday and Hasan (1976) treat collocation as words used in lexical cohesion of text and contain "a cohesive force". In terms of the degree of cohesiveness of lexical combination, Benson et al. (1986) state collocations are "fixed phrases" stored in the mind. Taking the pragmatic view of collocation, Nattinger and DeCarrico (1992) consider collocations as high frequency word combinations.

Cowie (1993) and Robins (1971) (cited in Herbst, 1996, p. 383) have defined collocation as the habitual association of a word in a language with other particular words in sentences such as white coffee, green with jealousy and maiden speech.

Regardless of any particular approach adopted, a number of studies e.g., Addison (1983); Dechert \& Lennon(1989); Bahns \& Eldaw, 1993; and Gitsaki (1996) were carried out using collocations from different dimensions. Addison(1983) in probing the concept of lexical collocations proposed these assumptions:

1) A text structure for a unit of discourse is analogous to that existing at the level of sentence.

2) A text form can become discordant if large enough samples of generically similar texts are examined.

3) An analogous text may be formed by studying the relationship between lexical collocation and topic/comment sequence.

Addison concludes that when a lexical set regularly occurs within the topic portion of sentences, the lexical set will be perceived as representing the point of the text, which can act as a whole theme of the text.

Some research has been conducted on the role of collocations in translation especially in translation of literary works and poetry. Recognizing the poet's style and his way of applying the lexical collocations can elucidate his attitude towards life

One of the most dominant characteristics of poets' compositions is the way they benefit from the lexical collocations. Sa'di took much advantage of lexical collocations to make his poetry more delicate and concise.

Most of the scholars of translation studies still stick to the notion of equivalence and believe that the more the translator makes use of equivalents of the source text terms in the target text the better will be the product of translation. These groups of scholars advise that in facing collocations, the translator must look for an equivalent collocation in the TL. This seems to challenging and time consuming and most of the time may be unproductive due to the cultural differences between SL and TL.

Newmark (1988) believes that the difficulty of translating collocations lies in two facts. First, the fact that there is an arbitrary relation between the collocates. Second, at least one of the components has a meaning not in a primary sense but in a secondary sense.

Baker (1992) mentions the arbitrariness between the constituents of a collocation and its meaning. She believes that we cannot talk of an impossible collocation since they can be frequently created. According to her, unusual combinations occur naturally because words tend to attract new collocate all the time. She states that the problem posed by collocations in translation is due to differences in the collocational patterning of the source and target languages. She lists five common pitfalls encountered in translating.

1. The engrossing effect of source text patterning

2. Misinterpreting the meaning of a source-language collocation.

3. The tension between accuracy and naturalness.

4. Culture-specific collocations

5. Marked collocations in the source text

Some Iranian scholars have also carried out research on the field. Mollanazar (1990) considered the role of collocations in translation. According to his studies well-structured combinations and normal sequences of words in source language change in the process of translation and become ill-structured in the target language. The abnormality created in the target text is due to the difference of linguistic features of collocations in SL in addition to the different meaning of the corresponding combinations in the two languages.

A similar study has been carried out by Shahriari (1997) about the restrictions of lexical collocations in translation. Different types of combinations of collocations which are equivalent in source and target languages are compared. Studies on the field of collocations and their importance in translation reveal that these investigations have a significant role in translation profession in that they form normal combinations and demonstrate unnatural ones.

\section{MeTHODOLOGY}

In this article, all the collocations used by Sa'di in his major work "Bustan" or "The Orchard" were examined and the translations of these collocations in two different translations were compared; One by Pazargardi, a Persian translator, and the other by an English translator, H. Wilberforce Clarke. The reason for choosing one Persian translator and one English speaker is to compare their translation to see the extent to which cultural information helps the translator 
translate collocation and to understand which of the cultures are more helpful in translating collocations; the source one or the target one.

Among all the collocations examined, because of their abundance, fourteen collocations are selected to present the analysis. The examination revealed some of the techniques these two translators employed in addition to merits and faults of each technique. It may help the translators to become aware of different strategies devised by different translators in tackling with translating collocations in poetry.

\section{DATA ANALYSIS}

Xas-o Xâr

كه ياكيزه به مسجد از خاك وخس

PF $^{1}$ : Gereftam qadam lâjaram bâz pas

PT $^{2}$ : Therefore, I decided to step out of it, for, a holy mosque should be free from rubbish.

$\mathbf{E T}^{3}$ : I consequently took the retreating step, saying: The Masjid pure of dust and chips (myself) is well

The Persian translator has used the word "rubbish" equivalent to the collocation marked in the original verse. He preferred to translate the collocational structure into a smaller level which is word level. The collocation " $x a \hat{k}$ - $o$ xas" is of the synonymous kind. Though " $x a \hat{k}$ " may be obvious to the translator, he fails to notice that "xas" completes the meaning of "xâk" in a way that together they mean something different from the meaning of each single word. "xas" changes the meaning of the collocation to "something unimportant which does not deserve any attention". Therefore, a meaning component is lost in the process of translation without any effort from the translator's side to compensate this lack of meaning. It seems when the translator fails to fully transfer the meaning of the collocation, he translates only one part of that collocation.

On the other hand, the English translator have not understood the meaning of the collocation and decided that a literal translation would suffice to overcome the problem. This latter point shows that the Persian collocation is a culturebound term.

Havâ-o Havas

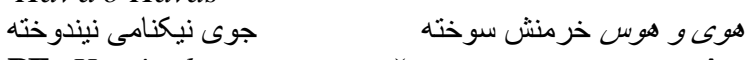

PF: Havâ-o havas xarmanaš su:xte ju:ye niknâmi nayanduxte

PT: Carnal desires had burnt up his harvest, and he had not stored even one grain of good name

ET: His harvest (of life) lust and concupiscence burned, a grain of good repute ungathered

The Persian translator preferred to use the adjectival phrase "carnal desires" as a correspondence for the Persian collocation "havâ-o havas" and Clarke who has understood only the meaning of "havas" has translated the collocation as a single word "lust" and failed to translate the word "havâ". The implied meaning of "havâ" in this context refers to the notion "wishing and desiring for something"

Ru:y-o Bar

نكون مانده از شرمسارى سرش

PF: Negu:n mânde ?az šarmsâri saraš

روان آب حسرت بهروى و برش

ravân ?abe hasrat be ru:yo baraš

PT: His head was bent with true shame, and tears were running down his face and body

ET: His head, in shame lowered, the water of remorse, with lamentation and desire running.

Pazargadi has translated the collocational term into "face and body". In the English phrase offered by him, "body" is considered as a correspondent for "bar" while this word means "face". The two words together refer to the head of the person. Clarke, on the other hand, sufficiently translated the collocation to nothing more than the mere notion of it. English translator ignored to translate the Persian collocation. The reason behind this decision is that since "ru:yo baro sar" all referred to head and face, he used the word "head" at the beginning of the sentence substituting for this collocation. The term "from his head" is the prepositional phrase for the verb "running" at the end.

Su:z-o Dard

كه آن راجكر خون شد از سوز و درد

PF: Ke ?ân râ jegarxu:n šod ?az su:zo dard

كر اين تكيه بر طاعت خويش كرد

gar ?in tekye bar ta?ate xiš kard

PT: For, his heart bled with pain and regret, while this one relied only on his devotion

ET: If the liver of that became blood, through heart-burning and sorrow, and if this one relied on his own devotion

In Persian culture, the term "xun jegaršodan" is used frequently as an idiom meaning "to suffer problems". It is not possible for the translator to present a word by word translation for most of the idioms are strictly culture-bound and this one is no exception. As we see, even the Persian translator failed to transfer the meaning of this idiom into English and this is because although he is acquainted with the culture of the source language, he is not well aware of that of the target one. As a result, he is consented with a literal translation. The point is that the literal translation given by the Persian translator has created a bizarre context which is not proper at all to convey the meaning to the English reader. The English translation is also unacceptable which is due to the unfamiliarity of the English translator with the

\footnotetext{
${ }^{1}$ Phonetic Form

${ }^{2}$ Persian Translator

${ }^{3}$ English Translator
} 
idiomatic expressions. This emphasizes the adherence of collocations to their related culture in addition to the importance of knowledge of idioms while translating a text of a culture distant from that of the translator.

?amre be ma? ruf va nahy? az monkar

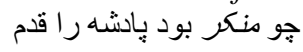

PF: čo monkar bovad pâdešah râ qadam

كه يارد زد از امر معروف دم؟

ke yârad zad ?az ?amre ma?ruf dam?

PT: But when indecency is committed by the royalty, who will dare speak of advising against awful deeds?

ET: When the foot of the prince is wicked, who is able to express a breath concerning the well-known order?

The collocation "?amr-e be ma?ruf va nahye ?az monkar" is originated from religious texts. Since it is not comprehensible to the English reader, both translators substitute a similar notion -more understandable to their readersfor that of the writer of the source text. In situations close to this one the translator considers transference of the gist of the writer's meaning as an adequate translation preferring it over a word by word translation. Despite the comprehensibility of the text translated, the delicacy of the poetry is lost in this technique. The reason is that collocating different words in a poem are done with considerable subtleties which are lost in translation.

Piš-o Pas

بسى كثت فرياد خو ان بيش و بِّ

PF: Basi gašt faryâdxân pišo pas

كه ننشست بر انكبينش مكس

PT: He kept on calling here and there for buyers, but not even a fly sat on his honey.

ET: Wandered much, before and behind, clamor-making, but, not a fly sate on his honey

As we see, two antonymous words came together to form this collocation implying "in different places". Pazargadi has fully understood this and used a proper combination in the target language which is frequently used by the target readers hence understandable for and familiar to them.

The English translator not knowing what the combination means drew on a word for word translation which is neither adequate nor a proper instrument to transfer the meaning of the source text. Mostly, when there is a relation of synonymous, antonymous or hyponymous kind between the two words in a collocation, it is much difficult for the translator to deal with the meaning in the translation process specially, on the account that the two words are used successively with no space between them. In similar situations, when the two words of these kinds of collocations are separated, it is much easier to translate them.

Xoft-o Xiz

ز فرياد و ناليدن و خفت و خيز

PF: Ze faryâdo nâlidano xofto xiz

كرفنتد از او خلق راه كريز

PT: Because of his cries and moans and his rise and fall, everyone took to his heels from him

ET: From his clamour, and lamenting, and sleeping, and rising, people took the path of flight from him.

This collocation is among those types which are rooted grammatically in verbs and due to the frequency of use, they have lost their primary meaning forming an idiomatic one instead. Pazargadi aware of the cultural maze of the source language has transferred it properly while Clark not knowing the idiomatic meaning of this collocation has contented himself with a word for word translation disregarding the idiomatic meaning of the collocation.

?asâye Kalim

عصاى كليم اند بسيار خوار

PF: ?asâye kalimand besyâr xâr

به ظاهر جنين زرد روى و نزار

PT: Like Kalim's staff they swallow profusely, though in appearance they are so pale and lean

ET: They are the staff of Musa, much-devouring, outwardly-so yellow of face, and emaciated.

The collocation in this verse is a Quranic one. So, the main point to have in mind in translating it is that understanding them needs Quranic knowledge and awareness of their historical background. In these cases, if the translator lacks awareness of the stories these collocations allude to, their efforts in translating them will possibly be unproductive. In the sentence above, the combination "?asâye kalim" will be understandable under the condition that the audience knows "kalim" is an appellation attributed to "Prophet Moses". The English translator avoiding the difficulty which can be raised for his readers for not knowing this uses the name "Moses" instead of the word "kalim" while the Persian translator keeps the proper noun "Kalim" beside the miracle related to Moses (PBH) together implying the meaning known to the Persian speaker but not familiar for the English reader.

Gir-o Dâr

نهبيى كز آن كبر و دار آمدش

PF: Nahibi kaz ?an giro dâr ?âmadaš

$$
\text { كريز بوقت اختيار آمدش }
$$

gorize bevaqt ?extiyâr ?âmadaš

PT: The fear caused by the shouts of catch thief, made him flee from there in time

ET: Through that tumult, fear came upon him, Flight, in season, became his choice

As we noticed earlier, one of the troubles that the translator faces when translating collocations, is related to those collocations originated from the verbs of the language. These terms prevent the translator from presenting a word for word translation. "gir-o dâr" means idiomatically "in that situation" which refers to the one in which a person was shouting. The translator explained the situation instead of using one single word or a similar group of words corresponding with the collocation in the source text. 
Clark, on the other hand, brought one single word "tumult" which seems an acceptable referent for the reader to understand the collocation. Therefore, it functions better than the descriptive terms given by the Persian translator supporting the conciseness which is one of the major features of Sa'di's poems.

Donya va ?oqbâ

بزرگى كه خود راز خردان شمرد

PF: Bozorgi ke xod râ ze xordân šemord

به دنبا و عقبى بزرگى بيرد

be donyâo ?oqbâ bozorgi bebord

PT: A great one who thought himself little, would win greatness in this world and the next

ET: The great one, who reckoned himself among the small folk, carried a way greatness in this and in the future world.

In this collocation, the word "donyâ" refers to this world and "?oqbâ" refers to the other world or the life after death. It is supposed that the English readers are in one way or another familiar with the notion of life after death and a literal translation will be sufficient to transfer the meaning. But the two translators fail to notice that the terms "the next world" and "the future world" lacks the meaning component of the life which comes after death. This improper equivalence restrains the meaning and causes ambiguity and suspension of the meaning. The poet's purpose was to mention that such a person he describes is a loser even after his death.

Baytolharâm

بدو كفت سالار بيث الحرام

PF: Bedu goft sâlâre baytolharâm

كه ای حامل وحى برنز خرام

ET: The chief of the sacred house (of the Kaba) spoke to him, saying: "Oh, bearer of the Divine Revelation! Move proudly higher"

The point worth mentioning about the difference between the two translators is that since the English one is sure his audience has very little knowledge about the terms related to Islam, he preferred to use the more familiar term "Kaba" instead of "Baytool-Haram" conveying the meaning in the best possible way. Pazargadi, on the other hand, overlooked the fact that his audience lack information about Islamic terms and inattentively used the same word as a proper noun. This technique makes the sentence unclear and difficult to understand.

Hu:r-o Pari

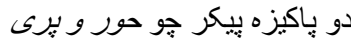

PF: Do pâkize peikar čo hu:ro pari

جو خورشيد و ماه از سديكر برى

čo xoršido mâh ?az sodigar bari

PT: They were as handsome and elegant as nymphs and fairies, and as glittering as the sun and moon, and superior to others

ET: Two pure forms like "hu:r" and "pari", like the sun and moon, free from a third likeness

Contrary to the previous one, we see that in translating this collocation each translator has taken totally different approaches. The Persian one aware of the meaning of the words "hur" and "pari" substitutes them with the words with a close meaning in English language which are familiar to the readers. While it seems that Clark could not understand the meaning of the words and considered the two words as proper nouns and consequently transliterated them into English to overcome the obstacle. This is another approach that a translator may adopt when he is not able to get the meaning and as a result, free translation becomes difficult.

Lahv va la?ab

مرا دستخاه جو انى برفت

PF: Marâ dastgâhe javâni beraft

بهل لهو و لعب زندكانى برفت

be lahvo la? ab zendegâni beraft

PT: I have lost the glory of my youth and wasted my life in worldly amusements

ET: The recourses of my youth have passed, life in play and pastime passed

The collocation "lahv-o la?ab" is an Arabic combination. Understanding derived words requires a precise inspection carried out on the roots of the words. In Persian language, this collocation refers to fun and entertainment in a way that busies the person with trivial thoughts. Pazargadi has translated it into "worldly amusement". The adverb "worldly" is a proper descriptive term. The English translator could not get the implication of the term and consequently, translated each word separately resulting in a word for word translation which lacks some of the meaning components of the original collocation.

Xâs-o ?âm

ملازم به دلدارى خاص و عام

PF: Molâzem be deldâriye xâso ?âm

ثناگوى حق بامدادان و شام

PT: He was in constant sympathy with high and low, and praised God mornings and evenings.

ET: Assiduous in the consolation of high and low, a praise-utterer of God, morning and evening

This collocation refers to the two different social states; the high social class and the low one. Together the two imply the whole people of all social classes. The Persian translator understood the meaning but his efforts in transferring it into English was a failure. The English translator probably could not understand the meaning of the combination. Since both translators could not find a suitable substitution for the source term, they decided to use the words " $h i g h$ " and "low" to indicate the different social classes. Thus, we see that when translators are not able to find appropriate terms to transfer the meaning of the source text terms, they draw on the term which has the nearest meaning to the source term. 


\section{CONCLUSION}

Regarding the subject of collocations and their importance in translation, the translator should take heed of some features of that collocation such as the constituents, the allusions behind them and the cultural implications transferred through collocations in translation of literary works when confronting a collocation. By investigating Sa'di's major work "Bustan" or as the west knows it "The Orchard", the abundance of collocations with a cultural or religious background in his poetry which he took advantage of to add to the delicacy and conciseness of his verse were observed. Through comparing two of the translations of his poems, the authors came to an understanding of the strategies employed by the two translators one Persian with a collocational information of the SL and the other an English speaker aware of the complexities of the TL and the target readers' culture. The aim was to find the different strategies they used and the merits and faults of each strategy. Through analysis of the selected collocations, the authors came to notice that although both of these types of information from the source culture and the target one are important, the translator should not fail to keep in mind the context of collocation as well as the cultural and religious differences between the two languages.

\section{REFERENCES}

[1] Addison, J. C. (1983). Lexical Collocation and Topic Occurrence in Well-Written Editorials: A Study in Form. In A. E. Fantini (Ed.), The Growth of word meaning. Cambridge: MIT

[2] Baker, M. (1992). In other words: A coursebook on translation. London: Routledge.

[3] Benson, M. (1989). The structure of the collocational dictionary. International Journal of Lexicography, 2(1), 1-14.

[4] Clarke, H. W. (1976). The Bustan of Sa'di. London: Imperial Organization for Social Services.

[5] Cruse, D. A. (1986). Lexical semantics. New York: Cambridge University Press.

[6] Dechert, H. W., \&Lennon, P. (1989). Collocational blends of advanced second language learners: A preliminary analysis. Contrastive pragmatics, 131-168.

[7] Firth, J. R. (1968). Descriptive linguistics and the study of English. Selected papers of JR Firth (1952-59), 96-13.

[8] Gitsaki, C. (1996). The development of ESL collocational knowledge. University of Queensland, Bangor.

[9] Halliday, M. A. K., \&Hasan, R. (Eds.). (1976). Cohesion in English (English Language). Essex: Longman.

[10] Herbst, T. (1996). What are collocations: sandy beaches or false teeth? English Studies 77(4), 379-393.

[11] Lyons, J. (1977). Semantics (Vol. 2). New York: Cambridge University Press.

[12] Mollanazar, H. (1990). The Role of Collocation in Translation, Unpublished. Tabiat Modarres University, Tehran.

[13] Nattinger, J. R., \&DeCarrico, J. S. (1992). Lexical phrases and language teaching. New York: Oxford University Press.

[14] Newmark, P. (1981). Approaches to translation. Oxford: Pergamon.

[15] Newmark, P. (1988). A textbook of translation. New York: Prentice Hall.

[16] Pazargadi, A. (2000). The Orchard (Boostan of Sa'di: the great poet of Iran). Tehran: Rahnama.

[17] Safavi, Kourosh. (2000). Semantics, Tehran: Soure Mehr Publications.

[18] Shahriari, Z. (1997). The Restrictions of Lexical Collocations and Translation. Islamic Azad University, Tehran.

[19] Sinclair, J. (1991). Corpus, concordance, collocation. New York: Oxford University Press.

[20] Stubbs, M. (1995). Collocations and semantic profiles: on the cause of the trouble with quantitative studies. Functions of language, 2(1), 23-55.

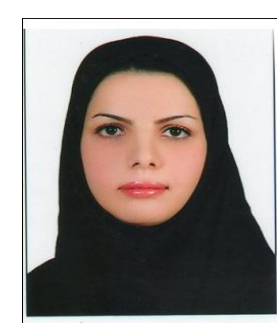

Shima Ebrahimi is an MA holder in linguistics. She received her BA degree in English Language and Literature in 2007 and MA degree at the Ferdowsi University of Mashhad in 2012, in the field of General linguistics. Her main research interests are semantics, pragmatics, examining the theoretical and practical issues in discourse analysis.

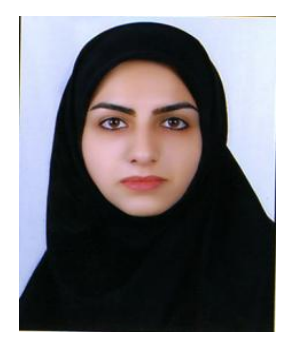

Fahimeh Lesan Toosi is a student of MA in Translation Studies in Ferdowsi University of Mashhad. Having graduated from Ferdowsi University with a BA in English Literature in 2010, she is experienced in teaching English as a foreign language to adult students as well as translating articles from Persian to English. She is interested in cultural studies related to translation and translation of literary works. 